\title{
RELATIONSHIP BETWEEN SAFETY CULTURE AND THE SAFETY CLIMATE, SAFETY BEHAVIOR, AND SAFETY MANAGEMENT
}

\author{
Dian Palupi Restuputri ${ }^{1}$, M. Syahban Giraldi ${ }^{1}$, Shanty Kusuma Dewi ${ }^{1}$, \\ Ilyas Masudin ${ }^{1}$, Uci Yuliati ${ }^{2}$ \\ ${ }^{1}$ Industrial Engineering Department, University of Muhammadiyah Malang \\ ${ }^{2}$ Management Department, University of Muhammadiyah Malang \\ e-mail : restuputri@umm.ac.id
}

\begin{abstract}
This article aims to measure the application of occupational safety and health using Cooper's Reciprocal Safety Culture Model and Confirmatory Factor Analysis method. The objective function of this article is to find out the aspects of safety culture that have been implemented by companies. A questionnaire was circulated to staff on the company's production floor as part of this study. The results of the questionnaire recapitulation were then analyzed using the confirmatory factor analysis method. Based on the score calculation results and the category determination build on the questionnaire scores on each dimension of the safety culture applied to the Steel Company, the safety climate value of 55.58 is obtained, which is on a 'quite good' scale. The safety behaviour value of 44,89 is included on a 'quite good' scale, the safety management system value of 22.04 is on a 'poor' scale, and the safety culture value of 40.83 is on the 'quite good' scale. With these results, it is essential to make improvements to the safety culture in the company, especially in the dimensions of the safety management system, which is on the 'quite good' scale.
\end{abstract}

Keywords: Occupational Safety and Health; Safety Culture; Safety Climate; Safety Behavior

Received: 2020-12-20; Revised: 2021-03-16; Accepted: 2021-03-27

\section{INTRODUCTION}

Safety culture is something that needs attention as it can have a positive impact on the company. An effective safety culture can help a company to maintain its reputation so that it brings some benefits. Safety culture is defined as a combination of perceptual attitudes and behaviours that produce performance output that can move the organization and as an embodiment of attitudinal behaviour and mutual understanding to create safety performance, which is understood and becomes the priority in the organization.

The steel industry is an industry where safe work procedures are very crucial to implement. It is because workers face many risks for the job. The work environment in the steel industry is usually hot and noisy, while the duties to do are tough, and there is always a risk of injury. Those who work in the steel industry have the largest number of cases related to occupational diseases, with 0.7 cases per 1000 workers. How good the safety procedures and regulations in an organization are considered to be influenced by the existing culture of the organization [1]. Safety culture is often cited as an important concept in understanding the state of safety in organizations [2]. Due to the high risk, as well as the importance of safety in the steel manufacturing context, the focus of this study is to examine the occupational safety culture in the steel manufacturing process.

Several previous studies of safety in the steel industry context have focused on behaviour, attitudes, climate, or culture, with results suggesting that culture can be the basis for unsafe attitudes and behaviours [3]. Security management commitment stands out among the previous findings as the main factor associated with positive safety culture, positive employee safety behaviour, and positive employee safety attitudes [4]. Relatively few empirical studies on safety culture so far have used qualitative methodologies [5, 6]. Qualitative methodology is considered suitable when investigating cultural values, while group norms are the focus of group 
interviews [7]. Culture is a complex phenomenon to study. With a perceptual survey (questionnaire), it is possible to study safety culture from one point of view; with a qualitative study approach, it is possible to do from another, which allows a more detailed and in-depth description, which can be carried out inductively.

Safety culture can be seen as one component of organizational culture, which refers to individual, job, and organizational characteristics that affect employee health and safety. The purpose of a positive safety culture is to create an atmosphere in which employees are aware of the risks they face in the workplace and are constantly aware of them [8]. Thus, safety culture can be considered important as a management tool helping to control workforce beliefs, attitudes, and behaviour related to safety [9]. Recognition of the importance of safety culture in preventing workplace accidents has led many people to define and assess many organizations [5].

Safety culture has become a special concern in developing countries, especially Indonesia. Research on Safety Culture in Indonesia has not been widely carried out, especially for the steel sector. The safety culture of a sector is certainly different from other sectors. The large portion of accidents caused by unsafe behaviour has made professionals develop various methods to deal with unsafe behaviour. One of the methods developed by professionals is the concept of safety culture. In short, this safety culture reflects a person's work safety level when no one is watching. This research takes a topic in the steel industry where there are many unsafe acts and work accidents. One hundred eighty-two accidents occurred during the period $2013-2018$. The incident rate is $2.98 \%$, with an average frequency of 19.37 accidents per 1,000,000 people working hours and severity of 0.716 lost workdays per $1,000,000$ people working hours $[10,11]$. The most dominant factors were unsafe behaviour (55\%) and unsafe condition (20\%) [10]. The Safety Culture aspect of Steel Company has not been going well, so several work accidents are still in the production process. The aim of this study was to investigate the relationship between safety culture with a safety climate, safety behaviour, and safety management system in the steel manufacturing industry by exploring worker's experiences and perceptions of safety and risk. Then, a study will be carried out to measure the safety culture level applied by the Steel Company with descriptive statistical tests using the method of Cooper's Reciprocal Safety Culture Model.

\section{METHODS}

\section{Cooper's reciprocal safety culture Model}

The research model is a reference in conducting research to be carried out. This model is used by research to predict the reciprocal relationship between its components. The components of the research are psychological factors, situations, and behaviours, which three components are also believed to be the causes of workplace accidents. The research model is a combination of research studies conducted by previous researchers. Research which shows that the components of psychological, situational, and behavioural factors apply to the chain of causes of accidents, among others, the research of [12], for example, identifies interactive relationships between behaviour, situations, and person factors at the operator level. The interactive relationship between management systems and managerial behaviour is also recognized by [13]. He states that accidents are a symptom of operational errors, also recognizes the interrelationship between the three factors and the time-related causal relationship between high-level strategic decisions. and operational errors. [14] the pathogenic model also recognizes that people, situational and behavioural factors are direct precursors of unsafe action. This reciprocal relationship is also recognized in work undertaken to identify organizational characteristics of occupational accidents, emphasizing the interactions between organizational systems, modes of organizational behaviour, and the psychological attributes of society [15]. The research results indicate that the three components are interrelated in forming a company's safety culture. A research model has been designed that describes Cooper's reciprocal safety culture model.

The research hypothesis checks whether each variable in Cooper's Reciprocal Safety Culture Model is feasible to represent safety culture as described in the model above. At this stage, the predetermined hypothesis will be tested using the Confirmatory method Factor Analysis where $\mathrm{HO}$ will be rejected if the loading factor value on the variable $<0.6$ and $\mathrm{H} 1$ will be accepted if the loading factor value at CFA>0.6. The hypothesis determined are as follows:

1. H 0: Safety Climate does not influence Safety Culture. 
H 1.1: Safety Climate influences Safety Culture. 2. HO: Safety Behavior does not influence Safety Culture.

H1.2: Safety Behavior influences Safety Culture. 3. H0: The Safety Management System has no effect on safety Culture.

H1.3: The Safety Management System has an influence on safety culture.

\section{Data Processing Using Confirmatory Factor Analysis (CFA) Second-Order Method}

At this stage, the data processing will be carried out based on the questionnaire recapitulation results using CFA. Data processing is conducted using the SmartPLS application. The data processing by using this method determines whether each dimension can affect the safety culture following the hypothesis made in the previous stage. The results of the CFA will show whether the variables are valid and reliable to represent Safety Culture.

In processing and analyzing data, the authors used score analysis to determine the application level of the Safety culture at the research location. There will be five values of the Safety culture implementation scale to be used based on the scores obtained from the research results. The five scale values will determine whether the implementation is considered not good, less good, quite good, good, and very good.

The analysis will be conducted on the previous results of data processing. It will be the company's consideration for implementing a safety culture in Steel Company to reduce occupational accidents. In the Reciprocal Cooper's Safety Culture Model method, the dimensions to be measured are the dimensions of the Safety Climate, Safety Behavior, and Safety Management System applied by the company with the indicators determined in this research questionnaire. Before taking the measurement, hypothesis testing will be conducted on every dimension that affects safety culture. The test uses the Confirmatory Factor Analysis and then calculates the results of the questionnaire recapitulation. The calculation is carried out using formula (2) to measure the implementation of the safety culture that has been implemented by the Steel Company. After calculating the questionnaire score, next is a description of the application of safety to Steel Companies based on the results of the scores.

\section{RESULTS AND DISCUSSION Data of Respondents}

Table 1 shows that the age of workers on the production floor of Steel Company has the highest frequency between 20 to 40 years, with a percentage of $53.44 \%$. Meanwhile, those above 40 years have a percentage of $46.56 \%$. The length of work with the highest percentage was respondents who worked less than equal to 3 years with a percentage of $32.76 \%$, followed with the length of work of more than equal to 10 years with a percentage of $25.86 \%, 4$ to 6 years with a percentage of $22.41 \%$, and length of work from 7 to 9 years with a percentage of $18.97 \%$. At the data collection stage, indicators of safety culture variables will be identified first. These indicators will be used as a questionnaire to measure the safety culture of the Steel Company. The variables to be measured are the dimensions of safety climate, safety behaviour, and safety management system. In this study, the safety climate will use the dimension which is adopted from the existing concept in Cooper's Reciprocal Safety Culture Model, which is in the personal dimension.

Table 1. Data of Respondent

\begin{tabular}{|c|c|c|c|}
\hline No. & $\begin{array}{l}\text { Age of } \\
\text { Workers }\end{array}$ & Frequency & Percentage \\
\hline 1. & $\begin{array}{c}20-40 \\
\text { years }\end{array}$ & 31 & $53.44 \%$ \\
\hline $\begin{array}{l}2 . \\
3 .\end{array}$ & $\begin{array}{c}>40 \text { years } \\
\text { Total }\end{array}$ & $\begin{array}{l}27 \\
58\end{array}$ & $\begin{array}{c}46.56 \% \\
100 \% \\
\end{array}$ \\
\hline
\end{tabular}

\section{Validation Test}

A validation test will be carried out to determine whether the answers to the questionnaire indicators have been declared valid. This validation test is carried out in 2 directions (2-tailed) with the value of $\alpha$ is $10 \%$ (risk of errors in making decisions). The indicator will be declared valid if the output value of $r$ count > r-table, where the r-table in this validation test is 0.2144 . Based on the Safety Climate variable, all variables are "valid" because the calculated $\mathrm{R}$-value on each indicator is greater $(>)$ than the R-table value. On indicator A1, the R-count value is $0.567>$ than the R-table value of 0.2144 . Based on the Safety Behavior variable, all variables are "valid" because the R-count value on each indicator is greater ( $>$ ) than the R-table value. On indicator $\mathrm{B} 1$, the R-count value is 0.418 > than the R-table value of 0.2144 . Based on the Safety 
Management System variable, all variables are "valid" because the R-count value on each indicator is greater $(>)$ than the R-table value. On indicator C1, the R-count value is 0.753 > than the R-table value of 0.2144 .

\section{Reliability Test}

At this stage, the reliability test will be conducted using the Cronbach Alpha method to determine whether the questionnaire is reliable or not. The questionnaire is considered reliable if the Cronbach alpha value is $>0.6$. The reliability test result on the Safety Climate variable shows that the questionnaire is reliable because the Cronbach alpha value is $>0.6$, which is equal to $0.874>0.6$. The reliability test result on the Safety Behavior variable shows that the questionnaire is reliable because the Cronbach alpha value is $>0.6$, which is equal to $0.846>0.6$. The reliability test result on the Safety Management System variable shows that the questionnaire is reliable because the Cronbach alpha value is $>0.6$, which is equal to $0.913>0.6$.

\section{Research Hypothesis Testing Using Confirmatory Factor Analysis}

At this stage, a validity test (convergent validity) will be conducted, aiming to determine whether the indicators are valid to measure a variable. The loading factor value will indicate this validation test. The indicators are said to be valid if the loading factor value is $>0.6$. Based on the measurement results, the loading factor value in the safety climate dimension is 0.963 . The result indicates that the loading factor value in the climate safety dimension is higher than 0.6. Therefore the safety climate dimension is declared valid. It means that Safety Culture can be measured by the Safety Climate, Safety Behavior, and Safety Management System dimension. Based on the results of the loading factor, it can be said that the desired hypothesis research is accepted.

The loading factor value on each variable is higher than 0.6 , so that the desired hypothesis can be accepted-the loading factor value in hypothesis $H_{0 . A}$ is $0.963>0.6$, so that the safety climate hypothesis does not influence safety culture is rejected. The loading factor value on $\mathrm{HA}$ is $0.963>0.6$, so that the hypothesis that safety climate influences safety culture is acceptable. It means that the safety culture can be represented by the safety climate, safety behaviour, and safety management system. From the results above, the conclusion is that the safety culture can be influenced and measured by the dimensions of the safety climate, safety behaviour, and safety management system. The highest loading factor value is in the safety management system dimension, which is 0.995 . The next is safety behaviour with a loading factor value of the ability of a safety management system to represent a safety culture is 99.5 .

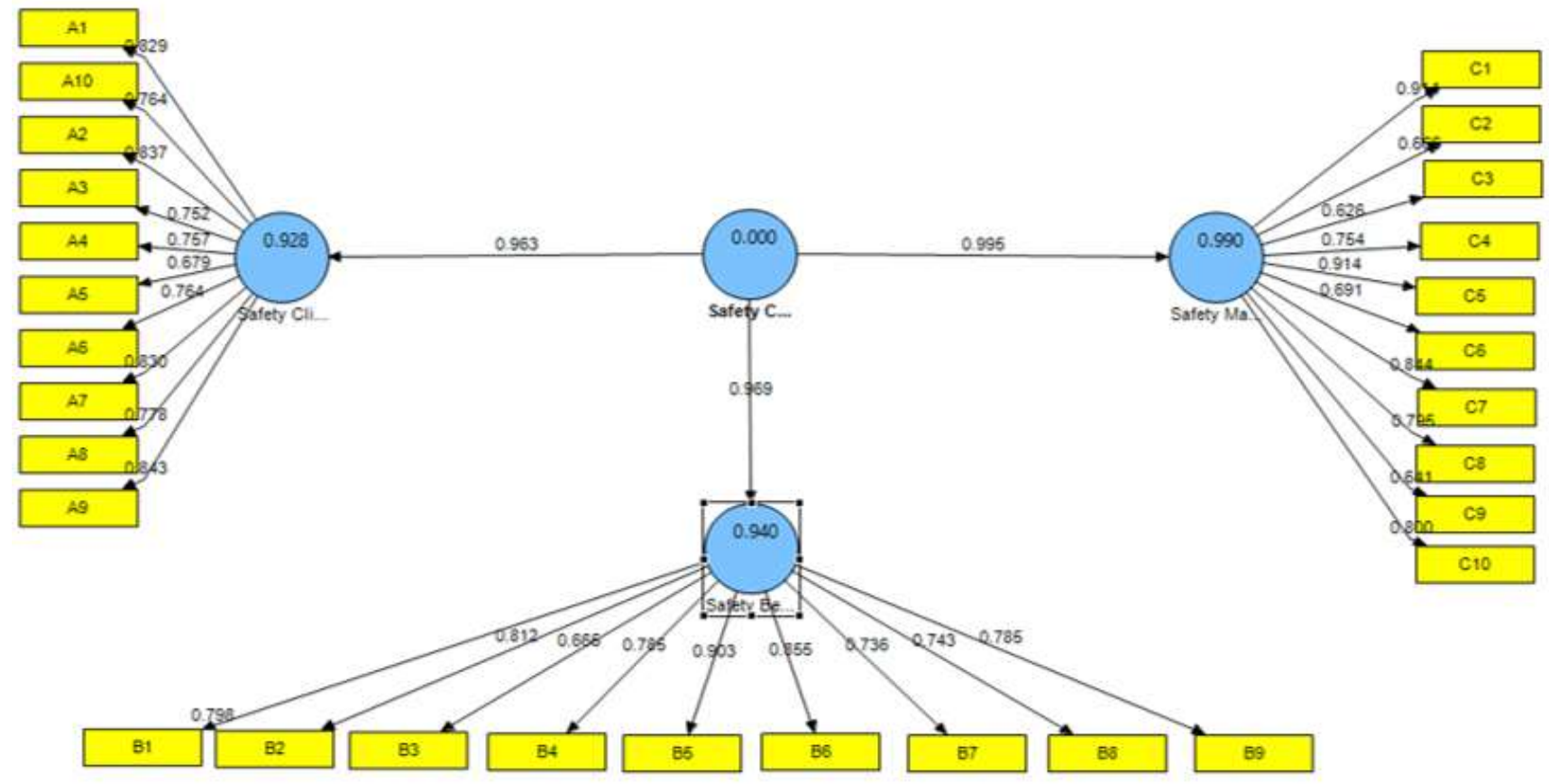

Figure 1. The output result of SmartPLS software 


\section{The Calculation and Determination of the Score-Category on Questionnaire}

At this stage, a questionnaire will be calculated to determine the level of Safety Culture based on predetermined categories, namely five categories (not good, less good, quite good, good, very good). Based on the calculation of the questionnaires, the score for the safety climate variable is 55,68 . Thus, it can be said that the safety climate is included in the "quite good" category. The score for the safety behaviour variable is 44,89 . Thus, it can be said that safety behaviour is included in the "quite good" category. The score for the safety management system variable is 22,04 . Thus, it can be said that the safety management system is included in the "less good" category. Based on the calculation of the Safety culture in table 2, it can be seen that the value of the occupational safety and health culture implemented by the Steel Company is 40.83 . This value is based on the three variable values in Cooper's Reciprocal Safety Culture Model, namely the value of safety climate, safety behaviour, and safety management system. From this value, it can be seen that the safety culture is included in the "Quite Good" category.

Table 2. The calculation results of the questionnaire score

\begin{tabular}{llll}
\hline No. & Variable & Score & Category \\
\hline 1. & Safety Climate & 55.58 & Quite Good \\
2. & Safety Behavior & 44.89 & Quite Good \\
3. & Safety Management System & 22.04 & Less Good \\
4. & Safety Culture & 40.83 & Quite Good \\
\hline
\end{tabular}

\section{Practical Implications The Analysis of Safety Management System}

At this stage, before proposing an improvement in occupational safety and health culture in the company, an analysis will be conducted on the safety management system aspects, which are still in the unfavourable category. At this stage, an analysis will be carried out on the indicators of the safety management system variable. The following is the root cause analysis for ten indicators:

1. Management does not blame workers when an accident occurs.

Based on the workers' answers in the indicator of 'management does not blame workers when an accident occurs', 62.07\% answered 'often'. It means that when an accident occurs at work, company management does not blame workers for the accident. Zohar and Hofmann [16] studied how the relationship between employees and supervisors can affect the safety of the work environment. Kath, Marks [17] found that high-quality supervisor-employee relationships involve open discourse around non-routine issues. With this finding, namely the application of communication, it is hoped that employees who have a strong relationship with their supervisors will feel more comfortable discussing safety issues with their supervisors. As a result, they will feel free to discuss even the smallest of issues with their supervisors to correct or avoid potential safety incidents.

2. Management tolerates workers taking dangerous actions when work schedules are busy.

Based on the workers' answers, $67.24 \%$ answered 'often' in the indicator of 'management tolerates workers taking dangerous actions when work schedules are busy. It means that the management tolerates workers taking dangerous actions when work schedules are busy. It is unsafe to implement so that it needs improvements. For the importance of organizational safety culture for safety outcomes, regulators have incorporated safety culture into their regulatory treasury [18].

3. Management is less able to handle safety issues in the right way.

Based on the workers' answers, 55.17\% answered 'often' in the indicator of 'management is less able to handle safety issues in the right way' the frequency of workers. It means that when an occupational accident occurs, management is less able to handle the issues in the right way. It also needs improvements. The safety leadership of the company leadership is one of the determining factors for improving safety performance that needs to be considered [19]. Reid, Flin [20] emphasized the importance of safety leadership for senior managers in improving safety performance. 
4. Management strives to design routine safety activities, which are useful and carried out correctly.

Based on the workers' answers, $67.24 \%$ answered 'often' in the indicator of 'management strives to design routine safety activities, which are useful and carried out correctly.' It means that the management strives to design routine safety activities, which are useful and carried out correctly. Research has shown that pressure from supervisors influences employee safety habits [21, 22]. If management supports safety procedures and is willing to invest in employees' safety, they are likely to feel more comfortable discussing safety-related issues with their supervisors [17].

5. Management doesn't care when a worker neglects safety.

Based on the workers' answers, 68.96\% answered 'often in the indicator of 'management doesn't care when a worker neglects safety' the frequency of workers'. It means that when workers ignore safety at work, management does not give sanctions to these violators. It is an indicator that the company needs to improve. An effective system improves safety only if an organization is willing to learn proactively and adapt its operations. An effective reporting system provides workers with timely and valuable feedback, informs them that their reporting has been reviewed and that appropriate actions will be taken [23]. If workers observe that their reporting of incidents or deviations does not lead to any action, they will revert to seeing them as part of the normal work process, and organizations will lose valuable opportunities for proactive improvements [23].

6. Management does not consider suggestions from workers regarding safety.

Based on the workers' answers, 56.90\% answered 'often' in the indicator of 'management does not consider suggestions from workers regarding safety' the frequency of workers.' It means that when an accident occurs, management does not consider the suggestions from the workers involved in the accident. This indicator is something that the company needs to pay attention to in future improvements. A positive Safety Climate is created when the interaction between organizations and project teams is guided in such a way that organizations ensure safe execution of projects, provide suitable and up-to-date personal protective equipment (PPE), and consider safety as their top priority [24]. Additionally, the commitment and involvement of management in workplace safety are critical factors in maintaining safety at a desirable level [25].

7. Management collects inaccurate information in accident investigations.

Based on the workers' answers, 68.96\% answered 'often in the indicator of 'management collects inaccurate information in accident investigations.' It means that in conducting an accident investigation, management does not collect accurate information. According to the literature, the main themes found in the safety leaders' perception of the safety culture factors were revealed [4]. The importance of leaders showing a commitment to safety and being visible to the project-based workforce was described as a key factor for a positive safety culture in the company.

8. Management ensures that everyone receives the necessary safety information.

Based on the workers' answers, $65.52 \%$ answered 'often in the indicator of 'Management ensures that everyone receives the necessary safety information.' It means that management has conveyed safety information to workers.

Safety climate is positively related to safety performance stated by Varone and Mattila [26]. Mearns, Whitaker [27] examined the relationship between workplace safety climate and subjective safety performance (self-reporting of safety behaviour) and objective safety performance (accident statistics), yielding only the "communication" dimension, which has an important role in predicting the relationship between safety climate and safety performance. [28]

9. Management ensures that any safety issues are encountered when safety checks/evaluations are handled immediately. Based on the workers' answers, 65.52\% answered 'often; in the indicator of 'Management ensures that any safety issues encountered when safety checks/evaluations are handled immediately.' It means that when an accident occurs, management guarantees the problem of the accident immediately during the inspection/investigation. Management needs to use appropriate approaches to seek feedback and suggestions from frontline workers who are in the best position to know how jobs should be performed safely [29]. Improving safety is maintained by organizations' willingness to learn proactively and to adapt their operations based on incident reporting [30]

10. Management encourages workers to participate in making decisions that affect their safety. 
Based on the workers' answers, more than $68.96 \%$ answered 'often' in the indicator of 'Management encourages workers to participate in making decisions that affect their safety the frequency of workers'. It means that when making decisions about safety, management has involved workers in participating. Leadership research examines the relationship between leadership and safety, which focuses on the supervisor and middle manager levels compared to examining the safety leadership of senior managers (company leaders) [20, 31].

\section{Relationship between Safety Culture and Safety Behavior}

Several other studies conducted by Shang and Lu [32] also reveal a positive relationship between safety climate, safety culture, and safety performance (self-reporting of safety behaviour). Another study conducted by Zhou, Fang [33] revealed that treatment of the safety climate has a positive effect that is significantly different from the improvement of workers' experience with safety. Safety is seen as a technical issue, and there is little awareness of the behavioural or attitudinal aspects of safety. The focus is on complying with rules and regulations [34]. Safety culture arising from [35] study Employees will interpret what managers say and do over a period of time and form their own opinions about the relative priority of safety. These interpretations will become significant cultural drivers for safetyrelated behaviour within an organization.

Safety culture is a subset of the wider organizational culture, and to develop a safety culture, it must be recognized that safety culture is about people, their organization, and interactions [36]. The organizational culture influences human behaviour and human performance at work and can be equally influential on safety outcomes as safety management systems themselves [37]. Thus aspects that need to be taken into consideration include the behaviours, perceptions, and attitudes of the people involved, the structure of the organization, internal communications, decision-making processes, management styles, and the like, as these directly affect attitudes, behaviour, and the motivations of those who have to do the work [38].

Leadership, organizational engagement, management commitment, preparation, and resource distribution were used to assess behavioural factors [39]. When compared to other behavioural variables, management engagement was ranked as the most critical [40]. Despite the fact that senior management believes and places a high value on management's dedication, this was not expressed in their organization's activities, as discovered. An effective reporting system is a keystone in identifying vulnerabilities associated with existing safety management before an accident occurs [30].

\section{Relationship between Safety Culture and Safety Climate}

Safety culture is derived from a historical context or organizational operations, values, and traditions and is generally created over a long period. The safety culture is the underlying belief that creates a climate. Safety culture is seen as a sub-facet of organizational culture [41, 42] and exists at a higher level of abstraction than safety climate [43]. Safety atmosphere is defined by day-to-day views of the working environment, working processes, organizational policies, and management and has a broader emphasis than safety culture. Thus, safety culture and safety climate appear to operate on different levels. However, due to the inherent stability of safety culture, it is considered to be an antecedent of individual behaviour. Employees may often be driven to action or inaction based on their perceptions of reality driven by the safety climate. Bhattacharya [38] examined the multilevel safety culture and climate to assess a newly launched safety program. They found the program's overall effectiveness in building a positive safety culture and climate [44]

\section{Relationship between Safety Culture and Safety Management}

According to Ostrom, Schroeder [45], organizations with a good safety culture also reflect on safety practices. Vredenburgh [46] did compile factors found across several reports concerning safety culture based on a few practitioners and experts [47, 48]. There are six management practices that have been discussed consistently concerning safety culture: (a) rewards, (b) training, (c) hiring, (d) communication/feedback, (e) participation, and (f) management support. There seems to be an agreement in general that management commitment is the driving force towards the achievement of a safety culture. [49] found safety culture could strengthen with the implementation of safety management systems. Furthermore, within the safety culture literature, it has been 
repeatedly shown that acts related to power distance are integral to effective safety management and are emblematic of a safe culture [50]. Management's commitment to safety stands out among earlier findings as a key factor associated with positive safety culture, positive employee safety behaviour, and positive employee safety attitudes [4]. Workers' belief in the safety values of the management has been linked to predicting worker risk behaviour [51].

\section{Safety Management System improvements of the Safety Culture in Steel Company.}

Based on the safety management indicators' analysis results, several indicators still need to be improved to implement occupational safety and health culture better. The safety management system is a formal documentation system for controlling potential sources of danger that are at risk of causing occupational accidents and diseases. The safety management system should be managed more effectively than other operational or production fields, even though what is written will differ from daily practice [52]. The goals and objectives of the OSH management system are to create an occupational safety and health system involving integrated management, labour, conditions, and work environment elements to prevent and reduce occupational accidents and diseases, as well as create a safe, efficient and productive workplace.

\section{CONCLUSION}

Based on the results of data processing using Cooper's Reciprocal Safety Culture Model and Confirmatory Factor Analysis method, it is concluded that the output of hypothesis testing using the confirmatory factor analysis method shows that the desired hypothesis is accepted. In other words, safety culture can be measured through the variables of safety climate, safety behaviour, and safety management system. Based on the results of the score calculation and the category determination build on the questionnaire scores on each dimension of the safety culture applied to the Steel Company, the safety climate value of 55.58 is obtained, which is on a 'quite good' scale. The safety behaviour value of 44.89 is included on a 'quite good' scale, the safety management system value of 22.04 is on a 'poor' scale, and the safety culture value of 40.83 is on the 'quite good' scale. With these results, it is very necessary to make improvements to the safety culture in the company, especially in the dimensions of the safety management system, which is on the 'quite good' scale. Based on the analysis results of the safety management system variable, which is on an unfavourable scale, the suggestion given is to determine OSH policies, implement predetermined policies, monitor and evaluate the implementation, as well as implement an effective safety management system.

\section{AUTHOR INFORMATION}

\section{Corresponding Authors}

Email: restuputri@umm.ac.id.

Phone: +62 85640000880

Email: muhammadsyahban.giraldi@gmail.com

Email: shanty@umm.ac.id

Email : masudin@umm.ac.id

Email : uci@umm.ac.id

\section{Author Contributions}

First Author, Second Author, Third Author, Fourth Author and Fifth Author have contributed equally to this work.

\section{REFERENCES}

[1] Guldenmund, F.W., Understanding and exploring safety culture. 2010.

[2] Edwards, J.R., J. Davey, and K. Armstrong, Returning to the roots of culture: A review and re-conceptualization of safety culture. Safety Science, 2013. 55: p. 70-80.

[3] Nordlöf, H., et al., Safety culture and reasons for risk-taking at a large steelmanufacturing company: Investigating the worker perspective. Safety Science, 2015. 73: p. 126-135.

[4] Biggs, S.E., et al., Safety leaders' perceptions of safety culture in a large Australasian construction organization. Safety Science, 2013. 52: p. 3-12.

[5] Glendon, I., Safety culture and safety climate: How far have we come and where could we be heading? Journal of Occupational Health and Safety-Australia and New Zealand, 2008. 24(3): p. 249-271.

[6] Hale, A.R., et al., Evaluating safety management and culture interventions to improve safety: Effective intervention strategies. Safety Science, 2010. 48(8): p. 1026-1035.

[7] Kitzinger, J., Qualitative research: introducing focus groups. BMJ, 1995. 311(7000): p. 299-302. 
[8] Ostrom, L., C. Wilhelmsen, and B. Kaplan, Assessing safety culture. Nuclear safety, 1993. 34(2): p. 163-172.

[9] Beck, M. and C. Woolfson, Safety cultureOne concept too many-Matthias Beck and Charles Woolfson with a contentious viewpoint on a vogue item on the safety menu. Safety and Health Practitioner, 1999. 17(1): p. 14-18.

[10] Ratih Damayanti, E.R., GAMBARAN KECELAKAAN KERJA DI INDUSTRI BAJA $X$ GRESIK INDONESIA. Journal of Industrial Hygiene and Occupational Health Vol, 2018. 2(2).

[11] Putri, R.M., Gambaran kecelakaan kerja dan determinannya di pt $\mathrm{x}$ tahun 20132018. 2019, UNIVERSITAS AIRLANGGA.

[12] Heinrich, H.W., D. Petersen, and N. Ross, Principles of accident prevention. Industrial accident prevention, 1980: p. 20-91.

[13] Collins, N.E. and E.C. Collias, Cooperative breeding behaviour in the white-browed sparrow weaver. The Auk, 1978. 95(3): p. 472-484.

[14] The reason, R.D., An examination of persistence research through the lens of a comprehensive conceptual framework. Journal of College Student Development, 2009. 50(6): p. 659-682.

[15] Smith, M.J., et al., Characteristics of successful safety programs. Journal of safety research, 1978.

[16] Zohar, D.M. and D.A. Hofmann, Organizational culture and climate. 2012.

[17] Kath, L.M., K.M. Marks, and J. Ranney, Safety climate dimensions, leader-member exchange, and organizational support as predictors of upward safety communication in a sample of rail industry workers. Safety Science, 2010. 48(5): p. 643-650.

[18] Kongsvik, T., G. Gjøsund, and K.M. Vikland, HSE culture in the petroleum industry: Lost in translation? Safety Science, 2016. 81: p. 81-89.

[19] Du, X. and W. Sun, Research on the relationship between safety leadership and safety climate in coal mines. Procedia Engineering, 2012. 45: p. 214-219.

[20] Reid, H., et al. Influence from the top: senior managers and safety leadership. In SPE International Conference on Health, Safety, and Environment in Oil and Gas Exploration and Production. 2008. Society of Petroleum Engineers.

[21] Vandenput, M.A., Unsafe habits and social pressures. Psychologica Belgica, 1970.
[22] Westaby, J.D. and J.K. Lowe, Risk-Taking Orientation and Injury Among Youth Workers: Examining the Social Influence of Supervisors, Coworkers, and Parents. Journal of Applied Psychology, 2005. 90(5): p. 1027.

[23] Lingard, H., et al., Health and Safety Culture. 2014.

[24] Mearns, K.J. and T. Reader, Organizational support and safety outcomes: An uninvestigated relationship? Safety Science, 2008. 46(3): p. 388-397.

[25] Hinze, J., M. Hallowell, and K. Baud, Construction-safety best practices and relationships to safety performance. Journal of construction engineering and management, 2013. 139(10): p. 04013006.

[26] Varone, U. and M. Mattila, The safety climate and its relationship to safety practices, the safety of the work environment and occupational accidents in eight wood-processing companies. Accident Analysis \& Prevention, 2000. 32(6): p. 761769.

[27] Mearns, K., S.M. Whitaker, and R. Flin, Safety climate, safety management practice and safety performance in offshore environments. Safety Science, 2003. 41(8): p. 641-680.

[28] Schutte, R., Safety Performance in the Construction Sector: The Influence of Transformational Leadership and the Mediating Role of Safety Climate. 2010.

[29] Maloney, W.F., I. Cameron, and B. Hare, Tradesmen involvement in health and safety. Journal of Construction Engineering and Management, 2007. 133(4): p. 297-305.

[30] Wiegmann, D.A., et al., Safety culture: An integrative review. The International Journal of Aviation Psychology, 2004. 14(2): p. 117134.

[31] Daniel, L., Safety leadership defined within the Australian construction industry. Construction Economics and Building, 2015. 15(4): p. 1-15.

[32] Shang, K.C. and C.S. Lu, Effects of safety climate on perceptions of safety performance in container terminal operations. Transport Reviews, 2009. 29(1): p. 1-19.

[33] Zhou, Q., D. Fang, and X. Wang, A method to identify strategies for the improvement of human safety behaviour by considering safety climate and personal experience. Safety Science, 2008. 46(10): p. 1406-1419. 
[34] Mengolini, A. and L. Debarberis, Safety culture enhancement through the implementation of IAEA guidelines. Reliability Engineering \& System Safety, 2007. 92(4): p. 520-529.

[35] Clarke, D.M. Cross-industry safety lessons of the Chernobyl disaster. In Safety and Reliability. 2011. Taylor \& Francis.

[36] Cox, S. and R. Flin, Safety culture: philosopher's stone or man of straw? Work \& Stress, 1998. 12(3): p. 189-201.

[37] Chan, A.P., et al., Evaluating the safety climate of ethnic minority construction workers in Hong Kong. Journal of Professional Issues in Engineering Education and Practice, 2017. 143(4): p. 04017006.

[38] Bhattacharya, Y., Measuring Safety Culture on Ships Using Safety Climate: A Study among Indian Officers. International Journal of e-Navigation and Maritime Economy, 2015. 3: p. 51-70.

[39] Ismail, F., et al., Assessing the behavioural factors' of safety culture for the Malaysian construction companies. Procedia-Social and Behavioral Sciences, 2012. 36: p. 573582.

[40] Lo, M.C., et al., The critical success factors for organizational performance of SMEs in Malaysia: a partial least squares approach. Revista brasileira de gestão de negócios, 2016. 18(61): p. 370-391.

[41] Weigmann, D., A synthesis of safety culture and safety climate. Urbana-Champaign, IL: the University of Illinois at UrbanaChampaign Aviation Research Lab, 2002.

[42] Cooper, M.D., Towards a model of safety culture. Safety Science, 2000. 36(2): p. 111136.

[43] Reichers, A.E. and B. Schneider, Climate and culture: An evolution of constructs.
Organizational climate and culture, 1990. 1: p. 5-39.

[44] Chen, Q. and R. Jin, Multilevel safety culture and climate survey for assessing new safety program. Journal of Construction Engineering and Management, 2013. 139(7): p. 805-817.

[45] Ostrom, E., L. Schroeder, and S. Wynne, Institutional incentives and sustainable development: infrastructure policies in perspective. 1993: Westview Press.

[46] Vredenburgh, A.G., Organizational safety: which management practices are most effective in reducing employee injury rates? Journal of Safety Research, 2002. 33(2): p. 259-276.

[47] Cohen, H.H. and R.J. Cleveland, Safety program practices in record-holding plants. Professional Safety, 1983. 28(3): p. 26-33.

[48] Pidgeon, N.F., Safety culture and risk management in organizations. Journal of cross-cultural psychology, 1991. 22(1): p. 129-140.

[49] Guldenmund, F.W., (Mis)understanding Safety Culture and Its Relationship to Safety Management. Risk Anal, 2010. 30(10): p. 1466-80.

[50] Chiang, H.Y. and G.A. Pepper, Barriers to nurses' reporting of medication administration errors in Taiwan. Journal of nursing scholarship, 2006. 38(4): p. 392399.

[51] Watson, G.W., et al., Dimensions of interpersonal relationships and safety in the steel industry. Journal of Business and Psychology, 2005. 19(3): p. 303-318.

[52] Kennedy, R. and B. Kirwan, Development of a hazard and operability-based method for identifying safety management vulnerabilities in high-risk systems. Safety Science, 1998. 30(3): p. 249-274. 